\title{
Research on Teaching Mode Reform of Robotics Course Based on "Theory Guidance- Interest Enhancement -Scientific Research Practice"
}

\author{
Qidan ZHU1, a, Li SU ${ }^{1, b,{ }^{*}, \text { Zhilin LIU }}{ }^{1, c}$, and Zhi ZHANG
}

${ }^{1}$ College of Automation, Harbin Engineering University, Harbin, Heilongjiang Province, China azhuqidan@hrbeu.edu.cn, ${ }^{\text {b}}$ suli406@hrbeu.edu.cn, ${ }^{c}$ liuzhilin@hrbeu.edu.cn, ${ }^{d}$ zhangzhi1981@hrbeu.edu.cn

Keywords: Teaching model reform, Cultivation of innovative talents, Robotics course.

\begin{abstract}
The key to creating an innovative country is to have innovative talents, and cultivating a large number of high-quality innovative talents is a major issue for higher education to solve urgently. This article takes the undergraduate of Harbin Engineering University as the main subject, carries out the research and practice of the teaching reform of the robot course based on "Theory Guidance - Interest Enhancement - Scientific Research Practice", and explores the training mode of high-quality innovative talents. The expectation of this article is to improve students' scientific research quality and innovation ability during the course of teaching.
\end{abstract}

\section{基于 “理论引导-兴趣提升-科研实践”的机器人课程教学模式改革研究}

\author{
朱齐丹 $1, \mathrm{a}$ ，苏丽 ${ }^{1, b}{ }^{*}$, 刘志林 ${ }^{1, \mathrm{c}}$, 张智 $1, \mathrm{~d}$ \\ ${ }^{1}$ 哈尔滨工程大学自动化学院, 哈尔滨, 黑龙江, 中国
}

azhuqidan@hrbeu.edu.cn, ${ }^{b}$ suli406@hrbeu.edu.cn, cliuzhilin@hrbeu.edu.cn, ${ }^{\mathrm{d}}$ zhangzhi1981@hrbeu.edu.cn

关键词：教学模式改革，创新人才培养，机器人课程

中文摘要. 创建创新型国家, 关键是拥有创新型人才, 培养大批高素质的创新人才是高等教 育亟待解决的一个重大课题。本文以哈尔滨工程大学自动化学院本科生为主体, 开展了基于 “理论引导-兴趣提升一科研实践”的机器人课程教学模式改革研究与实践, 探索高素质创新 人才培养模式, 以期在课程教学过程中提高学生科研素养和创新能力。

\section{1. 引言}

创新，是一个历久弥新的话题。进入 21 世纪以后，科技创新更是成为知识经济发展的灵 魂，深刻地改变着人类文明的基本构成和核心理念，作为科技创新活动主体的创新型科技人 才的培养, 也因此成为当今时代世界各国普遍关注的一个时代性课题。作为肩负我国人才培 养重任的各大高等院校, 也在不断进行适应我国国情的创新人才培养模式和课程体系改革 ${ }^{[1]}$ 。

我们认为学生创新能力的培养是一个循序渐进的过程，高等学校探索创新型人才培养模 式, 应该致力于课程教学模式和教学方法改革。通过教学模式和方法改革在教学过程中激发 学生创新思维和投身科研的兴趣, 继而进行科研实践达到循序渐进提高创新及实践能力的目 的。

以机器人实践为目的的设计、操作、编程等技术，涉及多领域的前沿技术集成，具备成 为大学生创新素质培养平台的条件 ${ }^{[2,3]}$ 。在大学生创新能力的培养过程中引入基于机器人课程 
实践的大学生创新素质培养机制, 改革课程教学内容是推进素质教育、提高学生的创新能力 的关键所在 ${ }^{[4,5]}$ 。

为此, 我们以哈尔滨工程大学自动化学院学生为实施对象, 以《机器人学导论》、《机 器人控制工程》、《工业机器人》以及《工业应用机器人技术分析》等一系列机器人课程为 试点, 开展了基于 “理论引导一兴趣提升一科研实践” 的机器人课程教学模式改革研究与实践。 通过机器人实践这种形式可使我们的创新人才培养找到一个好的切入点。通过培养学生亲手 操作、控制及规划一台实际机器人运动的能力, 将培训、设计、制作、调试与其涉及到的自 动化专业课程紧密地结合起来, 将实践融入到课本知识的传授中, 把多门相关学科有机的结 合起来, 以此达到对专业课程进行改革和对学生进行素质教育的目的, 增强学生的设计能力、 动手能力、创新能力和跨专业的综合应用能力, 从而最终提高学生的创造力和就业力。

\section{2. 基于机器人实践的机器人系列课程教学模式改革研究}

智能机器人融合了机械、电子、自动控制、传感器、计算机软硬件和人工智能等众多先 进技术。日本是世界上机器人教育水平和机器人文化普及水平最高的国家之一。在日本，不 仅每所大学具有高水平的机器人研究和教学内容, 且每年举行多种不同档次的机器人设计和 制作大赛, 通过大赛培养了大批机器人技术研究和应用人才, 使日本的机器人技术走到了世 界前列。在全世界范围内, 为了推动机器人技术的发展, 培养学生创新能力, 许多著名的高 校也相继出现了以培养学生为目的的机器人实践活动, 如机器人实验课程的设立, 机器人工 厂参观学习以及组织一系列的机器人竞赛, 目的就是为学生提供一种素质教育、创新教育与 前沿研究相结合的生动形式。相比国外高校, 我国高校在机器人实践教学和创新能力培养方 面存在只是结构不合理、实验教学薄弱和创新性实践内容不足等问题。

考虑到哈尔滨工程大学自动化学院开设了《机器人学导论》、《机器人控制工程》、《工 业机器人》以及 《工业应用机器人技术分析》等一系列必修和选修类机器人课程, 适合于作 为学生创新能力培养的综合性平台。因此, 自动化学院讲授上述相关课程的教师以这些课程 为试点, 以创新为主导, 学生为主体、以实践为中心, 研究新的教学模式和教学方法, 设计 了基于 “理论引导-兴趣提升一科研实践” 的机器人课程一条龙教学模式。该教学模式以多样 化的理论知识为引导, 以提升学生研究兴趣的各类实验和科研案例为支撑, 以科研实践和创 新创业训练为平台, 以期培养学生的创新意识和创新能力, 使之真正成为素质高、能力强的 创新拔尖人才。

\section{3. 基于 “理论引导-兴趣提升-科研实践” 的机器人课程教学模式改革与实践}

针对机器人系列课程的教学模式改革是基于机器人实践开展的。机器人操作与控制活动 几乎涉及到自动化专业的全部专业课程, 包括: 电路、电子技术、控制理论、单片机、DSP、 传感器、计算机语言、计算机控制等等。机器人实践是一个系统工程, 因此要把握总体设计 方案, 再进行合理分解, 变成一个个具有针对性的问题分别解决, 使学生全面掌握与机器人 操作控制等相关的知识, 并有目的地提高自己在某方面的实践能力和创新能力。在策略方案 分析中, 锻炼思考、分析问题和解决问题的能力; 在具体设计和调试中, 综合运用各门课程 知识, 提高工程实施的能力。使学生把课程理论与机器人实践活动紧密地结合起来, 提高学 生的动手能力、创造能力、协作能力和综合能力。

\section{1 基于 “理论引导一兴趣提升” 的机器人理论教学}

创新能力培养的基础是理论联系实际, 机器人基础理论仍然是机器人系列课程课堂教学 的主要内容, 但任课教师采取了新颖的呈现方式, 深化课堂教学方法改革。 


\section{(1) 课堂教学内容中要扩展机器人领域的先进基础理论}

考虑到自动化专业知识更新快, 专业课程易出现知识老化, 滞后于新理论发展的现象, 机器人系列课程的授课教师采用国际上公认的高水平教材, 并以网络互动教学作为互动交流 平台, 下载斯坦福大学、清华大学等知名大学的机器人专业的优秀课件、课堂视频以及实验 视频, 以此为基础结合国外高水平大学的教材, 合理规划教学内容, 推陈出新, 保证课程教 学内容的先进性。这种做法一方面以先进专业基础理论为引导, 促进了学生对基础理论的学 习和掌握; 另一方面, 国内外知名高校的课堂及实验视频可以激发学生对课程的学习兴趣和 热情。

（2）教学内容要增加实践性教学内容及相关实验的比例

一方面, 在机器人系列课程的教学中, 授课教师从自己所完成的、与机器人密切相关的 实际科研项目中抽取能够体现机器人理论与应用的科学问题和工程问题作为课例, 采用案例 式、互动式教学手段与学生一起分析和研讨, 理论充分联系实际, 帮助学生对知识点的消化 吸收, 极大的调动了学生的学习兴趣。而兴趣是最好的老师, 学生带着高涨的热情学习, 有 利于对机器人基础理论的学习和理解。

另一方面, 授课教师在课程中增加上机编程、实机试验、机器人操作等实践环节。编写 机器人实践教学手册, 通过讲授机器人操作与控制的相关知识, 加深学生对专业课程课堂教 学内容的理解和掌握。在相关专业课程中。结合课程特点和已有实验设备开发与机器人实践 相关的实验项目, 在实验过程中培养学生应用知识的能力。这些实验教学环节的扩充, 让学 生在亲自动手实践的过程中, 发现问题解决问题, 在进一步巩固专业基础知识的基础上, 对 工程实践有了初步的认识。

此外, 为了进一步培养学生的兴趣, 激发学生参与的积极性。机器人系列课程的授课教 师在全院开展机器人实践的宣传活动, 开展机器人讲座, 介绍机器人操作、控制的过程与相 关专业知识的联系。与课堂教学相辅相成, 激发学生学习热情, 点燃学生创新思维的火花。

\section{2 基于 “科研实践” 的机器人实践教学}

与传统的以知识传授和技能培养为目标的课程不同，机器人实践具有实践性强、探索性 强、应用性强和综合性强的特点, 有利于大学生迅速接触前沿研究, 提高大学生的创新能力 和专业素质。

机器人系列课程的授课教师均来自于自动化学院的机器人与智能控制研究所, 授课教师 结合研究所现有的机器人设备, 积极开展基于 “科研实践” 的机器人实践教学, 具体措施与 举措如下:

(1) 组织学生参观具备工业机器人设备的工厂及企事业单位, 让学生了解机器人在实际 工程中的应用过程;

(2) 前期授课教师已经从机器人与智能控制研究所的众多已完成的机器人项目中，选择 了难度适中的科研课题作为具有实际工程背景的课例补充到了课堂教学中, 在此基础上授课 教师针对这些工程课例构建实验环境, 让学生对这些课例进行复现, 对学生进行基本科研素 质和实践能力的熏陶;

(3) 授课教师利用机器人与智能控制研究所现有的机器人研究平台, 面向大一到大四的 学生, 组织学生进行科研立项、课程设计和毕业设计;

(4) 授课教师从研究所的在研科研项目中选择难度适中、有助于综合能力培养的科研课 题, 选拔优秀本科生参与科研, 与课题组的硕士、博士及相关教师共同攻关。在实施过程中 注意所选的科研问题的难度要适中, 并适时点拨, 对学生编程能力、动手能力、科研能力、 创新能力、团队协作能力进行培养; 
(5) 授课教师以所在的机器人与智能控制研究所为依托, 创办了 “机器人与智能控制大 学生创新创业训练协会” , 吸纳有潜质的本科生积极参与科创活动, 通过竞技类比赛锻炼创 新能力和综合素质。

\section{4. 结束语}

以哈尔滨工程大学自动化学院的机器人系列课程为例, 开展了基于 “理论引导-兴趣提升 一科研实践”一条龙的课程教学模式改革研究和实践探索, 试图利用课程教学的新模式和新方 法在教学过程中激发学生创新思维和科研热情, 并通过科研实践循序渐进地培养学生创新能 力。

\section{致谢}

本文为哈尔滨工程大学本科教学改革研究重点项目《基于 “理论引导-兴趣提升一科研实 践” 的机器人课程教学模式改革研究》(JG2016BZD08)、黑龙江省教育科学 “十三五” 规划 专项课题《以学生为中心的人才培养模式研究》（GBE1317040）、哈尔滨工程大学本科教学 改革项目《发挥专业优势的创新创业人才培养模式研究与实践》、哈尔滨工程大学研究生教 学改革研究项目《基于德式教学理念的研究生培养模式改革研究》（JG10217Y13）和哈尔滨 工程大学本科生品牌课程建设项目《现代控制理论》的阶段性成果之一。

\section{References}

[1] Li Su, Zhilin Liu, Xin Liu, Research on the construction of the "three leadings and five platforms" training model in the universities, Higher Education Forum, vol.8, pp. 22-23, 2015.

[2] Lin $\mathrm{Xu}$, Robotics course exploration of undergraduate teaching in intelligent specialty, Computer Education, vol.18, pp. 78-81, 2012.

[3] Yongchun Zhang, Jun Feng, Gang Wang, Jian Chen, Exploration of the training model of automation specialty for robot, Journal of EEE, vol.39, pp. 20-22, 2017.

[4] Xianghai Meng, Wei Wang, Teaching style of welding robot course in green skills development background, Industrial Technology and Vocational Education, vol.14, pp. 34-36,64, 2016.

[5] Rongchun Wan, Application of blended teaching in higher vocational welding robot course, Shipbuilding Vocational Education, vol. 5, pp. 54-57, 2017. 